\title{
Long-term fluctuations in cod and pollack along the Norwegian Skagerrak coast
}

\author{
Jean-Marc Fromentin ${ }^{1}$, Nils C. Stenseth ${ }^{1, *}$, Jakob Gjøsæeter ${ }^{2}$, Tore Johannessen ${ }^{2}$, \\ Benjamin Planque ${ }^{3}$
}

\author{
'University of Oslo, Department of Biology, Division of Zoology, Po Box 1050 Blindern, N-0316 Oslo, Norway \\ ${ }^{2}$ Institute of Marine Research, Flodevigen Marine Research Station, N-4817 His, Norway \\ ${ }^{3}$ Sir Alister Hardy Foundation for Ocean Science, The Laboratory, Citadel Hill, Plymouth PL1 2PB, United Kingdom
}

\begin{abstract}
We tested whether the long-term fluctuations in abundance of 0-group cod Gadus morhua and pollack Pollachius pollachius sampled from 1919 to 1994 at 38 stations along the Norwegian Skagerrak coast might be related to the North Atlantic Oscillation (NAO). The short-and long-term fluctuations of both species exhibited different spatial structures and were probably of different origins. The former, which were previously shown to be related to biotic interactions, displayed significant highest similarities across the smallest scales $(0$ to $21 \mathrm{~km})$. In contrast, the long-term fluctuations were similar at a larger scale (equal to or larger than the Norwegian Skagerrak coast) and were probably due to extrinsic factors. We have shown that the climatic conditions along the Norwegian Skagerrak coast and the fluctuations of Calanus finmarchicus in the Skagerrak were closely associated with the NAO. Long-term fluctuations of cod and pollack were, however, not associated linearly or non-linearly with the NAO or C. finmarchicus. Trends of cod and pollack appeared to be related to the long-term fluctuations in the bottom sea grass coverage, mainly constituted by Zostera marina, and it cannot be dismissed that fishing has contributed to the recent decline of these fish populations. We also conclude that the postsettlement period is crucial for these populations because of competition for space.
\end{abstract}

KEY WORDS: Gadus morhua . Pollachius pollachius - North Atlantic Oscillation - Time series analyses - Calanus finmarchicus

\section{INTRODUCTION}

In a previous study on 0-group cod Gadus morhua and pollack Pollachius pollachius sampled from 1919 to 1994 at 38 stations along the Norwegian Skagerrak coast, Fromentin et al. (1997) showed that abundance of both species exhibited periodic fluctuations of 2 to 2.5 yr as well as similar long-term trends. Results from modelling on the Norwegian Skagerrak cod (Bjørnstad et al. unpubl., Stenseth et al. unpubl.) give strong support to the hypothesis that the 2 to 2.5 yr cycle was caused by biotic interactions, such as competition for space and food and/or cannibalism between the juveniles stages (Fromentin et al. 1997). However, the origins of the long-term trends, which account for an

·E-mail: n.c.stenseth@bio.uio.no important part of the temporal variations, appeared more obscure and were not elucidated.

Here, we tested whether the long-term fluctuations of the Norwegian Skagerrak cod and pollack might be related to a large-scale climatic oscillation, the North Atlantic Oscillation (NAO; Rogers 1984). The past few years have seen an increasing number of studies presenting evidence of relationships between large-scale physical oceanographic processes and year class strength of different fish stocks (see Mann \& Lazier 1991 or Mann 1993 for a review). Several mechanisms have been put forward to explain these links, such as: emigration of the larvae due to changes in oceanic currents (Dickson \& Brander 1993), changes in the vertical mixing and in the stratification of the water masses which affect the planktonic production (e.g. Sverdrup 1953, Dickson et al. 1988, Cushing 1989) and subsequently the fish stocks (Harris et al. 1992, Beamish \& 


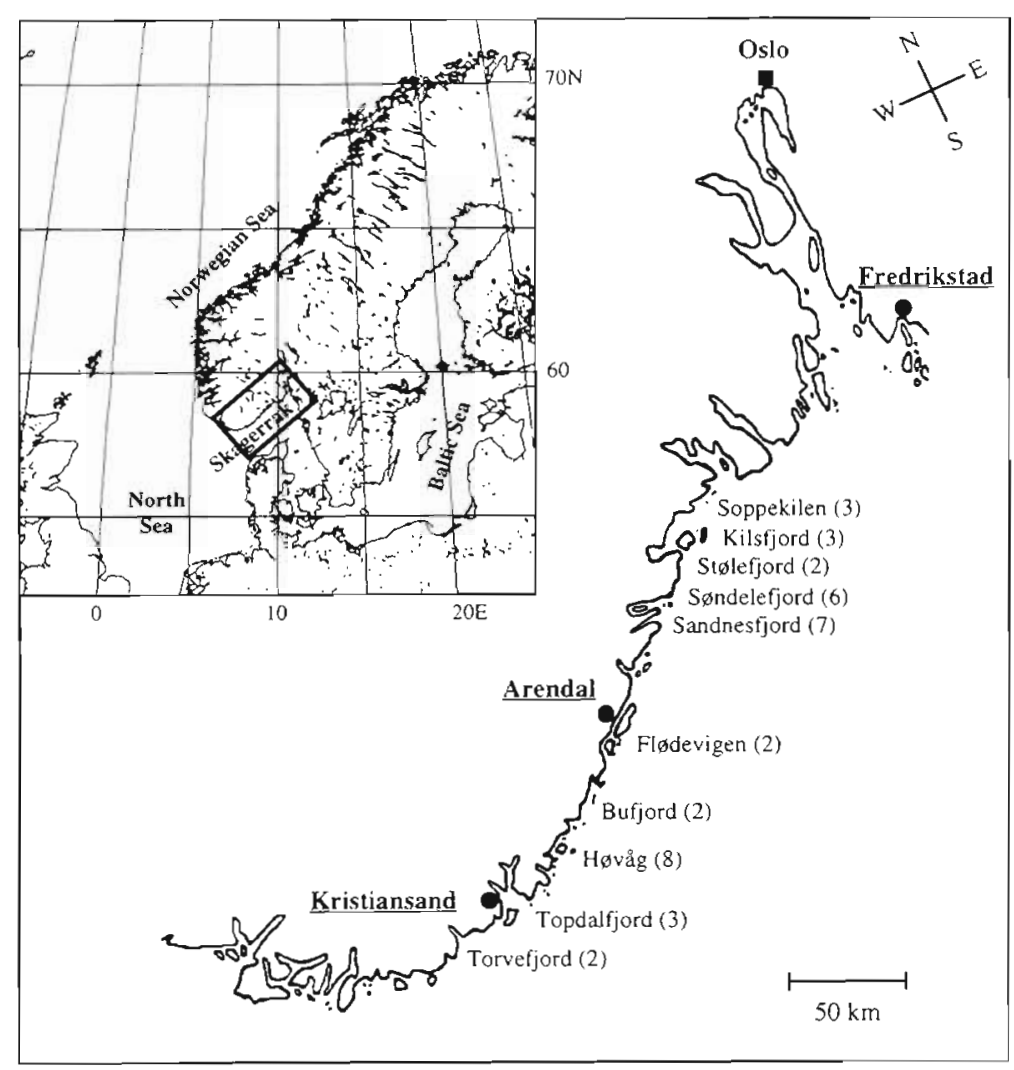

Fig. 1. Inset: Location of the Norwegian Skagerrak coast in northwestern Europe. Main map: location of the 38 stations studied along the Norwegian Skagerrak coast. The 38 times series (stations) were obtained from an extensive research survey and were sampled from 1919 to 1994 . For each area or fjord ( 10 in all), the number of stations is given in parentheses. Kristiansand, Arendal and Fredrikstad are the 3 locations where meteorological data were collected

Bouillon 1993), effects of wind intensity on the dispersion of prey of the fish larvae (Lasker 1981, Cury \& Roy 1989), effects of changes in temperature on growth rate of fish (Brander 1995), and combined effects of changes in temperature and wind (Ottersen \& Sundby 1995). The NAO governs the pattern and strength of the wind, temperature and precipitation over the North Atlantic, Northeast American and Western European coasts (Hurrell 1995). It also has profound effects on physical oceanographic processes (Rogers 1990, Cayan 1992a, b, Dickson et al. 1996). For all these reasons, the NAO could affect directly and indirectly the fish stocks from the North Atlantic and the adjacent seas.

Fromentin \& Planque (1996) have furthermore shown that variations in abundance of Calanus finmarchicus over the Northeast Atlantic were closely linked to the NAO. The decline of $C$. finmarchicus during high NAO episodes probably results from a tremendous increase of wind strength, which delays and depletes the phytoplankton production, as well as from high temperature, which is unfavourable to the cold temperate C. finmarchicus (Hirche 1987, Planque \& Fromentin 1996). Because $C$. finmarchicus constitutes the main food resource of the fish larvae in the Northeast Atlantic (Ellertsen et al. 1981, Skreslet 1989, Brander \& Hurley 1992), the NAO directly relates to the match/ mismatch hypothesis (Cushing 1990, Brander \& Hurley 1992), according to which the strength of a year class depends on the timing between the fish larvae and their zooplanktonic food. The NAO is also relevant to the match/mismatch hypothesis in its less restrictive sense (Myers et al. 1993), which only requires a general correspondence between larval production and planktonic food. In both cases, the NAO could thus affect fish stocks through food availability for the fish larvae.

This work tested whether the NAO, through some of the mechanisms described above, could cause the long-term fluctuations in the Norwegian Skagerrak cod and pollack. To test this hypothesis, we first examined the spatial scales of the temporal fluctuations of cod and pollack to determine whether the long-term fluctuations could be induced by largescale environmental events. Second, we checked the link between the NAO and the meteorological conditions over the Norwegian Skagerrak coast as well as between the $\mathrm{NAO}$ and Calanus finmarchicus in the Skagerrak, to corroborate the influence of the NAO in the studied area. Then, we investigated, through various statistical techniques, the relationship between the NAO and the Norwegian Skagerrak cod and pollack. We further considered the influence of the variations in the bottom sea grass coverage and fishing on the long-term fluctuations of cod and pollack.

\section{MATERIAL}

Cod and pollack time series. Among the Flødevigen data set (for more details, see Gjøsæter 1990, Johannessen \& Sollie 1994), we studied data of 0-group cod and pollack sampled from 1919 to 1994 at 38 fixed stations (Fig. 1). In contrast to Fromentin et al. (1997), we excluded the whiting Merlangius merlangus from this study, since this species displayed a high spatial het- 
erogeneity (much higher than cod and pollack). It would therefore have been difficult to obtain reliable conclusions about a possible impact of a large-scale oscillation on whiting. The sampling took place each year in September/October and the series consisted of 1 abservation per year. Because the metamorphosis of the fish larvae in these populations occurs in late spring, the 0-group corresponds to half-year-old juveniles. The 38 stations were classified into 10 different regions, each containing from 2 to 8 stations (Fig. 1). Torvefjord, Bufjord, Flødevigen and Stølefjord correspond to coastal areas directly open to the Skagerrak, whereas the coastal areas Høvåg and Soppekilen are enclosed. Topdalfjord, Sandnesfjord, Sondelefjord and Kilsfjord are typical fjords. The maximum distance between stations is about $210 \mathrm{~km}$.

The North Atlantic Oscillation. The NAO is the major source of interannual variability in the North Atlantic atmospheric circulation (Rogers 1984, Lamb \& Randy 1987, Mann \& Lazier 1991). It results from the oscillation of the subtropical high surface pressures, centred on the Azores, and of the subpolar low surface pressures, centred on Iceland. The NAO is measured by an index (Fig. 2) that is the difference in normalised air pressures at sea level (SLP) between Ponta Delgadas (Azores) and Akureyri (Iceland; SLP were provided by the World Weather Archive). Although the NAO is evident throughout the year (Alexander \& Deser 1995, Hurrell \& Van Loon 1998), the index is usually calculated over the winter season (December to March), when the NAO is most pronounced (Rogers 1984). For this reason and because most of the important marine biological processes, such as the onset of planktonic production or the release and hatching of fish eggs, occur at the end of the winter, we used the winter index. The state of the NAO determines the speed and direction of the wind across the North Atlantic, as well as temperatures on both sides of this ocean. An accentuated pressure difference between the Azores and Iceland (corresponding to a high positive NAO index) is associated with a strong westerly wind circulation in the North Atlantic, high temperatures in western Europe and low temperatures in Greenland and eastern Canada, and vice versa. Persistence of an exceptionally strong positive phase of the NAO seems further to be the source of recent temperature anomalies and changes in atmospheric moisture transport (Hurrell 1995). Schlesinger \& Ramankutty (1994) suggested that the NAO explains $55 \%$ of the interannual variations in global temperature.

Air temperature, sea surface temperature and wind over the Norwegian Skagerrak coast. Air temperature (AT), sea surface temperature (SST) and wind records were provided by the Norwegian Meteorological Insti-

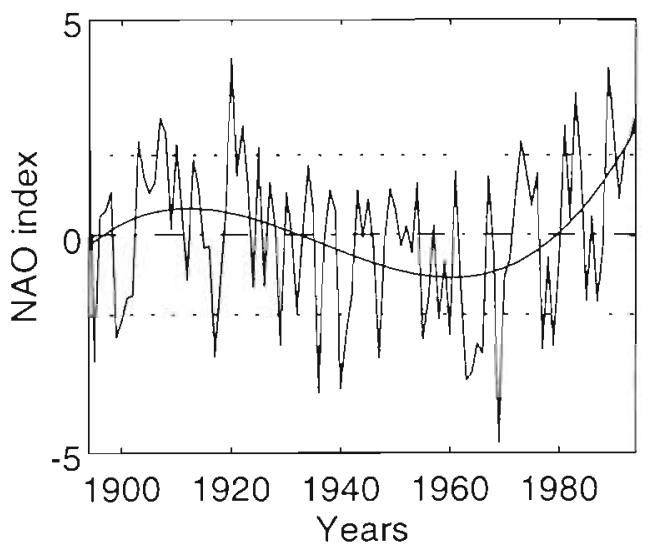

Fig. 2. North Atlantic Oscillation index, based on the average winter pressure difference between the Azores and Iceland, from 1894 to 1994 (Rogers 1984). The trend is estimated by a third-order polynomial function. Dash-dotted line indicates the mean of the series and dotted lines the mean $t 1$. standard deviation

tute. The meteorological data were collected at 3 different locations across the Norwegian Skagerrak coast: Kristiansand (south), Arendal (middle) and Fredrikstad (north) (Fig. 1), from 1920 to 1994 for AT, 1947 to 1994 for SST and 1957 to 1994 for wind. Westerly wind (WW) corresponds to the speed of the wind for the directions between $200^{\circ}$ and $290^{\circ}$. WW constitutes the dominant direction of the wind along the Norwegian Skagerrak coast $(\sim 40 \%)$, whereas the secondary dominant direction is the north-northeast one $(\sim 30 \%)$, which occurs in opposition to WW. To check the spatial consistency of AT, SST and WW over the studied area, we simply investigated, for each meteorological variable, the correlation between the 3 time series corresponding to the 3 locations. As we used the winter index for the NAO, we first computed the winter series of AT, SST and WW (average over the winter months December to March).

Calanus finmarchicus. Data were provided by the Continuous Plankton Recorder survey (CPR; Warner \& Hays 1994). The CPR is a high-speed plankton sampler designed to be towed from commercially operated 'ships of opportunity' over long distances. The CPR is towed in the surface layer ( 7 to $8 \mathrm{~m}$ depth) and, due to mixing induced by the ship towing the CPR, the layer from 0 to $20 \mathrm{~m}$ is sampled. Each sample corresponds to 20 nautical miles $(37 \mathrm{~km})$, that is about $3 \mathrm{~m}^{3}$ of filtered sea water. For the present study, we used data on copepodites stage $V$ and adults sampled from 1958 to 1992 (see Planque \& Fromentin 1996 for more details). From the eastern North Atlantic, where the sampling was constant and regular during the period (Warner \& Hays 1994), we selected an area corresponding to the Skagerrak: $57^{\circ}$ to $59^{\circ} \mathrm{N}, 7^{\circ}$ to $12^{\circ} \mathrm{E}$ (Fig. 1 ). 
Variation in abundance of Calanus finmarchicus in the Skagerrak is likely to reflect abundance in the Norwegian Skagerrak coastal waters, because several of the stations are located in areas with direct exposure to the Skagerrak, or in fjords whose copepod abundance is mainly regulated by water exchange processes with the open sea (Lindahl \& Hernroth 1988).

\section{METHODS}

Cod and pollack data were log-transformed (natural logarithm) to stabilise the variance (Sen \& Srivastava 1990). Such a transformation is also biologically reasonable since population dynamics are mostly governed by multiplicative processes (Williamson 1972). Before logtransformation, a constant of unity (the lowest catch value) was added due to the occurrence of zeros.

From 1940 to 1944 , during the Second World War, the sampling was interrupted at almost all the stations (see Fromentin et al. 1997). Interpolating these 5 consecutive years was impossible because of the extensive variability inherent in these biological time series. From 1919 to 1939,29 time series (i.e. stations) of the 38 were complete, and 9 series included 1 or 2 missing values. From 1945 to 1994, 35 stations were complete and 3 stations had 1 to 3 missing values. These short gaps were interpolated using the ZET method. This method, proposed by Zagoruiko \& Yolkina (1982), is an iterative procedure based on regression that estimates the missing values within a matrix by taking into account the correlation between the columns (the stations) and between the lines (the years), as well as the number of missing values within each column/line. Each species was then represented by a matrix of 38 series of log-abundance across 71 years (the 1919 to 1994 period less the years from 1940 to 1944). Analyses were conducted separately for cod and pollack.

Detection of spatial structure. To determine the scale of the physical and biological processes affecting recruitment patterns (see Myers et al. 1995), we first performed the Mantel test (Mantel 1967) to check whether the similarity between the 38 time series of each species depends on their geographical locations. For each species, we calculated a matrix of ecological distances, $\mathrm{X}$, corresponding to the distances between the 38 time series (as 1 minus the pairwise correlation coefficient). The second matrix of distances, $Y$, contained the geographical distances (in $\mathrm{km}$ ) among the 38 stations. The Mantel test is analogous to the linear correlation between $\mathbf{X}$ and $\mathbf{Y}$ (Smouse et al. 1986). The null hypothesis, $H_{0}$, of this test is: the ecological distances in matrix $\mathbf{X}$ are not linearly related to the geographical distances in matrix $\mathbf{Y}$. In order to distinguish the spatial structure of short-and long-term fluctua- tions in cod and pollack abundance, we generated for each species 3 matrices of ecological distances, $\mathbf{X}$, containing the distances between: (1) the non-detrended series (i.e. the log-transformed data), (2) the detrended series (i.e. the series of log-transformed data minus the trend estimated by a third-order polynomial function) and (3) the trends alone (as estimated by the thirdorder polynomial). A Mantel test was then performed between each matrix $\mathbf{X}$ and the matrix $\mathbf{Y}$ (3 tests for each species). Due to interdependence between distances, a permutation test was used to evaluate the level of significance (Legendre \& Fortin 1989). Repeatedly permuting at random the geographical matrix, followed by the recomputation of the correlation, produced an empirical null distribution against which the actual value of the correlation was tested (10000 permutations were done for each Mantel test).

Estimation of spatial scale. The Mantel test only indicated whether the similarity between the time series was dependent on the distances between stations, but this test did not provide information on the scale of the spatial structure. This was done by calculating the Mantel correlogram (Sokal 1986, Legendre \& Fortin 1989), which describes how the correlation between stations varies with distance. Practically, this test consisted in calculating the local average of the pairwise correlation between stations included in a given class of distances. We used 10 classes of distances. As the largest distance between stations is $210 \mathrm{~km}$, each class of distances covered approximately $21 \mathrm{~km}$ - i.e. the Mantel correlation for the first class of distance corresponded to the mean similarity between $\mathrm{X}$ and $\mathrm{Y}$ for all the stations less than $21 \mathrm{~km}$ apart; the value for the second class of distances was the mean correlation for stations 22 to $43 \mathrm{~km}$ apart; and so on The value of the Mantel correlation for a given class of distances is positive when the similarity within this given class is higher than the average similarity (for all the classes of distance) and negative when the similarity is lower. The correlation between stations decreases with distance; therefore, the spatial scale on which the biological time series exhibit higher similarities may be evaluated by the first class of distance for which the Mantel correlation is equal to or less than zero (Legendre \& Fortin 1989).

Detection of synchronicity between variables. Relationships between the NAO, the meteorological variables, cod, pollack and Calanus finmarchicus were first investigated with the Pearson correlation coefficient. Because of temporal positive autocorrelation, the assumption of independence between years is violated. Consequently, the estimation of the number of degrees of freedom is biased (Ostrom 1987). In the meteorological variables and in the NAO time series, significant positive autocorrelation occurs at lag 1 and 
at lags $>10$ (because of long-term cycles and trends; see Fig. 4). To deal with autocorrelation due to longterm fluctuations, we computed correlation on both non-detrended and detrended time series. The comparison between both allowed us to distinguish whether a significant correlation between 2 nondetrended series was due only to the presence of the trends or not. We corrected the bias due to the autocorrelation at lag 1 (on the non-detrended as well as on the detrended series) by adjusting the degrees of freedom with the method proposed by Bartlett (1946) (see also Priestley 1981):

$$
N^{\prime}=N \frac{1-a_{1} a_{2}}{1+a_{1} a_{2}}
$$

where $N$ is the number of pairs of observations in the 2 series and $N^{\prime}$ is the adjusted number of degrees of freedom assuming an AR(1) process $\left(a_{1}\right.$ and $a_{2}$ being the lag 1 autocorrelation coefficients of the 2 series).

For cod, pollack and Calanus finmarchicus, autocorrelation on non-detrended series occurred at most of the lags because of the strong declines in abundance in the 3 series (see Figs. $5 \& 6$ ). On the detrended series, no significant autocorrelation occurred for Calanus finmarchicus and only a significant negative autocorrelation at lag 1 for cod and pollack (which reflects the 2 to 2.5 yr cycle detected by Fromentin et al. 1997). There was therefore no need for corrections for autocorrelation in these series.

Analysis of extreme events. Analysis of extreme events was performed by applying Superposed Epoch Analysis (Haurwitz et al. 1981, Prager \& Hoenig 1989). This method is a statistical test to assess the influence of extreme events of a given environmental variable on a biological variable (in our case, fish abundance). Allowing the relationship between an environmental variable and fish abundance to be non-linear and nonmonotonous, this method investigated relationships that correlation analysis could not detect. In our application, SEA is based on the null hypothesis, $H_{0}$, that there is no association between extreme values of the NAO index (low or high) and the abundance of cod and pollack. The test was conducted by comparing fish abundance in key-event years (defined as extreme events) to abundance of fish in adjacent years. To perform this test, we first defined key-event years as those in which (1) the values of the NAO index were higher than the average plus 1 standard deviation (high NAO) and (2) the values of the NAO index were lower than the average minus 1 standard deviation (low NAO; see Fig. 2). Adjacent years were defined as the years before and after the key-event year (we tested for 1 year before and after as well as for 2 years before and after). Three different statistics can be calculated to compare abundance in key years with abundance in adjacent background years (see Prager \& Hoenig 1989). As the results led to similar conclusions, we presented only the results from the $W$-statistic, which is considered to be the most powerful one (Prager \& Hoenig 1989). To test for significance, we used a Monte Carlo randomisation procedure as described by Prager \& Hoenig (1989). Repeatedly permuting at random the locations of the key-event years in the environmental series (i.e. the NAO time series), followed by the recomputation of the $W$-statistic, produced an empirical null distribution against which the actual value of the $W$-statistic was tested (5000 permutations were made to form the empirical distribution).

\section{RESULTS}

\section{Spatial scales of short- and long-term fluctuations of cod and pollack}

As indicated by the significant Mantel correlation coefficients on the non-detrended series, the similarity between the time series of 0 -group cod and pollack was not independent of their geographical locations (Table 1). The Mantel correlograms performed on these series clearly indicated that the highest similarities occurred at the smallest scales ( 0 to $21 \mathrm{~km}$; Fig. $3 \mathrm{a}$, b), i.e. proximate stations were significantly more similar than distant ones. The Mantel correlation coefficients computed on the detrended series were higher (Table 1), indicating that the spatial dependence was higher for short-term fluctuations. The Mantel correlograms displayed similar results, with a spatial structure at a local scale (0 to $21 \mathrm{~km}$; Fig. 3c, d). The trends alone showed no spatial structure at the scale of the study. The Mantel correlation coefficients were close to zero and non-significant (Table 1). As expected in this case, the Mantel correlograms were flat (Fig. 3e, f).

These results indicate that the similarities at a local scale $(0$ to $21 \mathrm{~km})$ were due to the short-term fluctua-

Table 1. To distinguish the spatial structure of short- and long-term fluctuations, different Mantel tests were performed: on (1) the non-detrended series (log-abundance data), (2) the detrended series (log-abundance data minus the trend estimated by a third-order polynomial function) and (3) the trend alone, for both cod and pollack. A permutation test was used to evaluate the level of significance (10000 permutations were performed for each test). ' Significant at the $0.1 \%$ level, " significant at the $1 \%$ level, ${ }^{\text {ns }}$ non-significant

\begin{tabular}{|lll|}
\hline & Cod & Pollack \\
\hline Non-detrended & $0.25 \cdots$ & $0.18 \cdots$ \\
Detrended & $0.28 \cdots$ & $0.26 \cdots$ \\
Trend & $0.01^{\mathrm{ns}}$ & $0.03^{\mathrm{ns}}$ \\
\hline
\end{tabular}



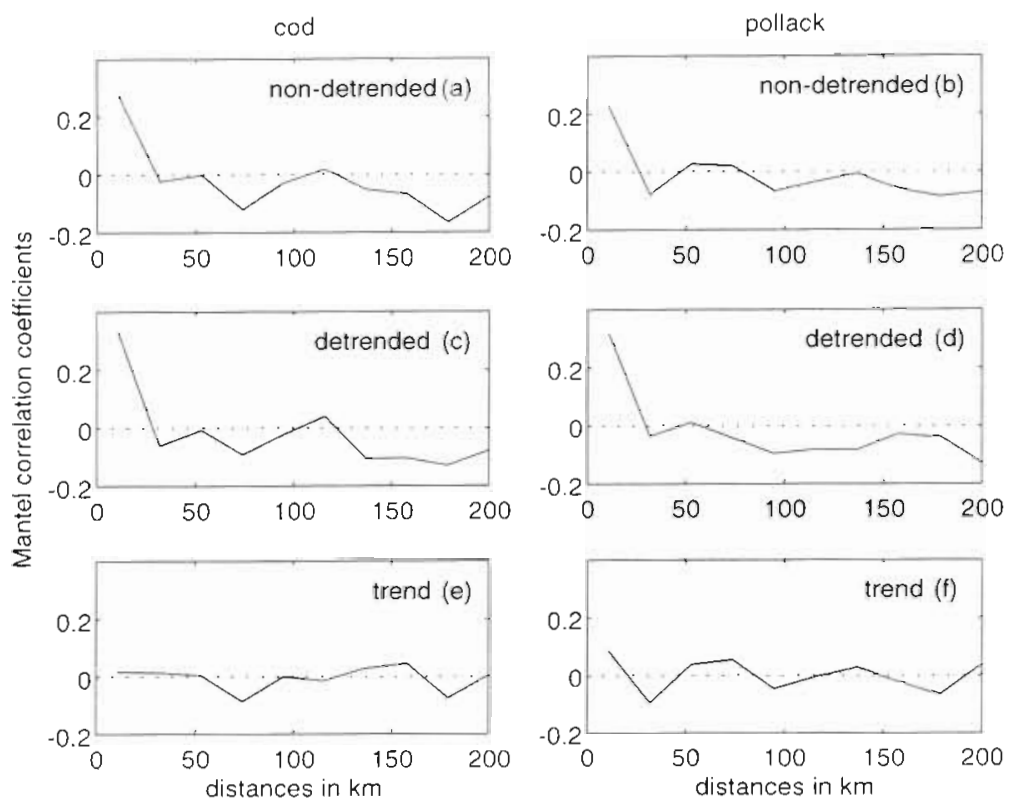

Fig. 3. Results of the Mantel correlograms computed for 10 classes of distance on the different time series of cod abundance (left column) and pollack abundance (right column). The value of the Mantel correlation for a given class of distance is positive when the similarity within this class is higher than the similarity among all classes of distance, and negative when the similarity is lower. The correlation between stations decreases with distance, and the spatial scale is given by the first class of distance for which the Mantel correlation is equal to or less than zero. Results shown were obtained using $(a, b)$ the non-detrended series (log-abundance), $(c, d)$ the detrended series (i.e. $\log$-abundance data minus the trend estimated by a third-order polynomial function), $(e, f)$ the trend alone one location to another. The correlation coefficients between the 3 winter series of each variable were very high and significant at the $0.1 \%$ level: $0.99,0.95$ and 0.98 for AT, SST and WW, respectively (Table 2). Hence, meteorological conditions all along the Norwegian Skagerrak coast displayed a low spatial variability. We therefore averaged each variable over the 3 locations to obtain one series for AT, one for SST and one for WW, describing the mean winter fluctuations of these variables along the Norwegian Skagerrak coast.

Comparisons of the NAO with AT, SST and WW were performed to evaluate the relationship between the $\mathrm{NAO}$ and the meteorological conditions along the Norwegian Skagerrak coast. The NAO index and winter series of AT from 1920 to 1994 were highly and significantly correlated $(r=0.67, p<0.1 \%$; Table 3$)$. These 2 series showed fairly similar trends and synchronous year-to-year fluctuations (Fig. 4a). High AT were observed in years of high NAO index and vice versa. This was corroborated by a high and significant correlation between detrended series ( $\mathrm{r}=0.66$, $\mathrm{p}<0.1 \%$; Table 3) and by the linear regression (Fig. 4b). Similar conclusions could be drawn from the comparisons be- tions. In contrast, the long-term trends did not display similarity at a local scale. This may be explained by assuming that either: (1) the 38 stations did not exhibit similar trends to each other; or (2) the trends were similar among all the 38 stations, so that the trends were a global feature that could not be detected at the scale of the study. Fromentin et al. (1997) have shown that cod and pollack displayed similar long-term trends at 78 and $95 \%$ of the stations, respectively. This indicates that the long-term trends of both species were a global feature and that the spatial structure of the trends occurred at a scale equal to or larger than the scale of the study. It was, therefore, relevant to test for a possible relationship between large-scale climatic variables and the long-term trends of cod and pollack.

\section{Influence of the NAO on meteorological conditions over the Norwegian Skagerrak coast}

Comparisons of the 3 winter series of each meteorological variable (i.e. at the 3 different locations) indicated that temporal variations were highly similar from
Table 2. Pearson correlation coefficients between the winter series of air temperature, sea surface temperature and westerly wind at 3 different locations, Kristiansand, Arendal and Fredrikstad). ${ }^{\cdots}$ Signuficant at the $0.1 \%$ level

\begin{tabular}{|lcc|}
\hline & $\begin{array}{c}\text { Air temp. } \\
\text { Kristiansand }\end{array}$ & $\begin{array}{c}\text { Air temp. } \\
\text { Arendal }\end{array}$ \\
\hline $\begin{array}{lcc}\text { Air temp. Arendal } \\
\text { Air temp. Fredrikstad }\end{array}$ & $0.99 \cdots$ & - \\
& $0.99 \cdots$ & $0.99 \cdots$ \\
& $\begin{array}{c}\text { Sea temp. } \\
\text { Kristiansand }\end{array}$ & $\begin{array}{c}\text { Sea temp. } \\
\text { Arendal. }\end{array}$ \\
\hline Sea temp. Arendal & $0.96 \cdots$ & - \\
Sea temp. Fredrikstad & $0.94 \cdots$ & $0.95 \cdots$ \\
& & \\
& West wind & West wind \\
& Kristiansand & Arendal \\
\hline West wind Arendal & $0.98 \cdots$ & - \\
West wind Fredrikstad & $0.97 \cdots$ & $0.98 \cdots$ \\
\hline
\end{tabular}


Table 3. Pearson correlation coefficients between the NAO index and the series of air temperature, sea surface temperature and westerly wind (each meteorological series resulting from the average of the series at the 3 locations given in Table 2). Normal typeface: non-detrended series (raw data); italics: detrended series (raw data minus the trend estimated by a third-order polynomial function). ' ${ }^{\prime}$ Significant at the $0.1 \%$ level

\begin{tabular}{|lccc|}
\hline & NAO & A.r temp. & Sea temp. \\
\hline Air temp. & $0.67 \cdots$ & - & - \\
& $0.66 \cdots$ & & \\
Sea temp. & $0.60 \cdots$ & $0.97 \cdots$ & - \\
& $0.59 \cdots$ & $0.97 \cdots$ & \\
West wind & $0.77 \cdots$ & $0.83 \cdots$ & $0.82 \cdots$ \\
& $0.71 \cdots$ & $0.81 \cdots$ & $0.81 \cdots$ \\
\hline
\end{tabular}

tween NAO and SST (Table 3, Fig. 4c, d), and NAO and WW (Table 3, Fig. 4e, f). These results indicate that fluctuations in AT, SST and WW were closely associated with the NAO.

\section{Relationship between the NAO and cod and pollack}

To test for relationships between the NAO, cod and pollack, we computed the average of the log-abundance over the 38 stations for both species. We thus obtained a vector of 71 values (an average time series of the log-abundance of each species from 1919 to 1994 excluding the years 1940 to 1944).

Correlation coefficients between the NAO index and the log-abundance of cod and pollack from 1919 to 1994 were low and non-significant (Table 4). Trends of the NAO on the one hand and of cod and pollack on the other were very different (Fig. 5a, c). From 1919 to 1939 the NAO and both cod and pollack displayed a downward trend, whereas from 1945 to 1994 the trends of the NAO and both fishes were opposite. Year-to-year fluctuations were also very different (Fig. 5a, c): years of low NAO might correspond either to high abundance in cod and pollack (e.g. 1964, 1966, 1979) or to low abundance (e.g. 1936, 1947), and vice versa. The regression plots (Fig. 5b, d) confirmed the previous findings. By per-
Fig. 4. (a, c, e) Times series of (a) air temperature $\left({ }^{\circ} \mathrm{C}\right)$ from 1920 to 1994 , (c) sea surface temperature $\left({ }^{\circ} \mathrm{C}\right)$ from 1947 to 1994 and (e) westerly wind intensity $\left(\mathrm{m} \mathrm{s}^{-1}\right)$ from 1957 to 1994 along the Norwegian Skagerrak coast. These series (solid lines) correspond to winter averages (means over December to March). The NAO index for the corresponding period is shown by the superimposed dotted line. All the series were previously standardised. The trends are estimated by a third-order polynomial function. (b, d, f) Linear regression plots between the NAO index and the meteorological variables
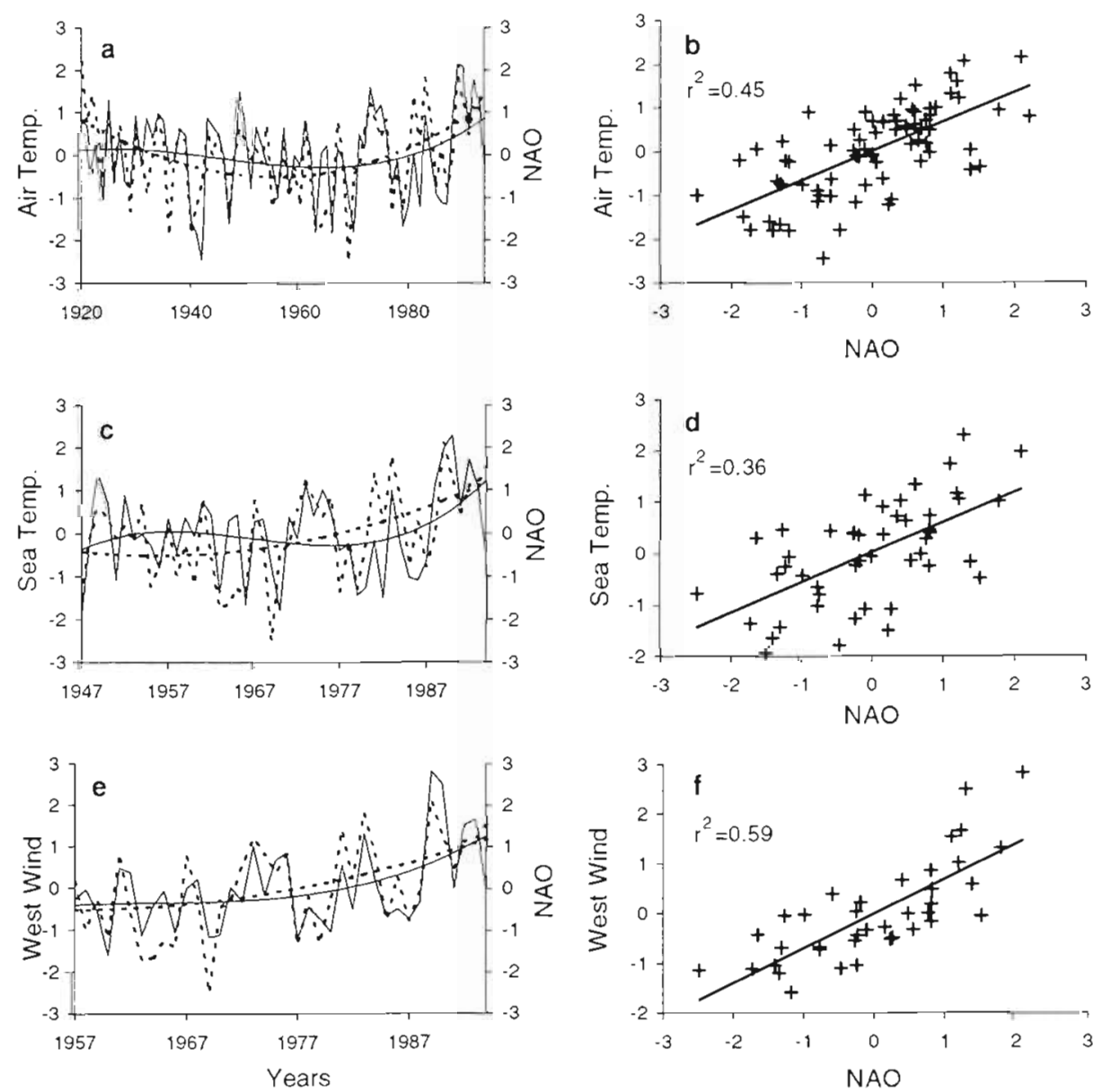
Table 4. Pearson correlation coefficients between the NAO index, cod and pollack from 1919 to 1994 (averaged series over the 38 stations) and Calanus finmarchicus from 1958 to 1992. Normal typeface: non-detrended series; italics: detrended seres. $\cdots$ Significant at the $0.1 \%$ level, ${ }^{\prime}$ significant at the $1 \%$ level, "significant at the $5 \%$ level, ${ }^{n s}$ non-significant

\begin{tabular}{|lclc|}
\hline & NAO & Cod & Pollack \\
\hline Cod & $-0.04^{\mathrm{ns}}$ & - & - \\
& $-0.01^{\mathrm{ns}}$ & & \\
Pollack & $-0.002^{\mathrm{ns}}$ & $0.57^{\cdots}$ & - \\
& $0.09^{\mathrm{ns}}$ & $0.41^{\cdots}$ & \\
C. finmarchicus & $-0.58^{\cdots}$ & $0.4^{\circ}$ & $0.38^{\cdot}$ \\
& $-0.50^{\circ}$ & $0.12^{\mathrm{ns}}$ & $0.05^{\mathrm{ns}}$ \\
\hline
\end{tabular}

forming the Superposed Epoch Analysis (SEA), we tested for non-linear and non-monotonous relationships and checked whether abundances of cod and pollack were related to extreme NAO events. For both species, there was a lack of association between extreme NAO events and the level of abundance of cod and pollack (Table 5a, b). Results from correlation analyses and SEA indicate that the temporal fluctuations of cod and pollack could not have been related to the $\mathrm{NAO}$, even though meteorological conditions along the Norwegian Skagerrak coast were closely associated with the NAO.

\section{Relationship between Calanus finmarchicus and cod and pollack}

Calanus finmarchicus in the Skagerrak from 1958 to 1992 (Fig. 6a) was closely related to the NAO, as shown by Fromentin \& Planque (1996) over the Northeast Atlantic. The trends were opposite, the NAO displaying a regular increase and $C$. finmarchicus a decrease. Year-to-year fluctuations were synchronous; periods of high NAO were associated with low abundance of C. finmarchicus (e.g. 1972-1976, 1983 and 1989-1992), whereas periods of low NAO were associated with high abundance of C. finmarchicus (e.g. 1962-1966, 1977-1980). These findings were confirmed by the high negative correlation, being significant at the $1 \%$ level on both non-detrended and detrended series (Table 4), as well as by the linear regression (Fig. 6b). Analyses of extreme events showed that high NAO events induced significantly lower abundance of $C$. finmarchicus during the keyevent years than the following years (Table 6), whereas low NAO events induced significantly higher abundance during key-event years than the previous years (these results were even more conspicuous when analyses were performed for 2 years).

The decline of Calanus finmarchicus in the Skagerrak is likely to influence mainly the larvae of cod and pollack, since juveniles of demersal fishes mainly feed on bottom fauna. Fish larvae are most abundant in
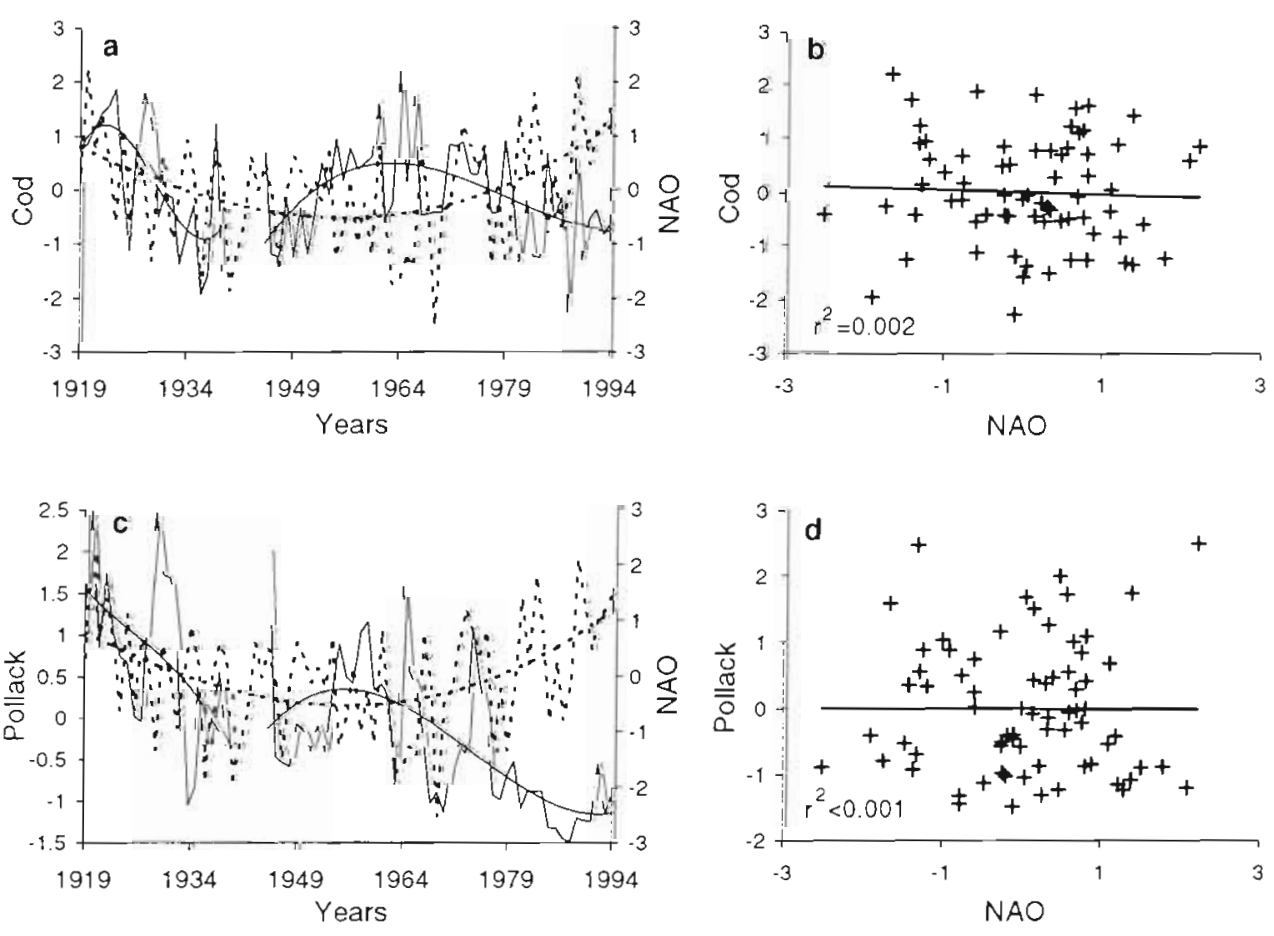

Fig. 5. $(a, c)$ Average of the log-abundance of (a) cod and (c) pollack across the 38 stations from 1919 to 1994 (excluding the years 1940 to 1944). The NAO index for the corresponding period is shown by the superimposed dotted line. All the series were previously standardised. The trends are estimated by a third-order polynomial function. (b, d) Linear regression plots between the NAO index and cod and 
Table 5. Results of the Superposed Epoch Analysis of the NAO key events as related to the log-abundance of (a) cod and (b) pollack. Analyses are based on the $W$-statistic (Prager \& Hoenig 1989). p value was estimated from a permutation test (5000 permutations were performed) for 1 and 2 years before the key-event year; 1 and 2 years after; and 1 and 2 years before and after

\begin{tabular}{|c|c|c|}
\hline Number of key events: & $\begin{array}{l}\text { High NAO } \\
8\end{array}$ & $\begin{array}{c}\text { Low NAO } \\
15\end{array}$ \\
\hline \multicolumn{3}{|l|}{ (a) Cod } \\
\hline \multirow[t]{3}{*}{$p$ value for 1 year: } & 0.31 & 0.36 \\
\hline & 0.33 & 0.48 \\
\hline & 0.43 & 0.37 \\
\hline \multirow[t]{3}{*}{$p$ value for 2 years: } & 0.39 & 0.41 \\
\hline & 0.38 & 0.46 \\
\hline & 0.33 & 0.41 \\
\hline \multicolumn{3}{|l|}{ (b) Pollack } \\
\hline \multirow[t]{3}{*}{$\mathrm{p}$ value for 1 year } & 0.10 & 0.35 \\
\hline & 0.40 & 0.65 \\
\hline & 0.15 & 0.50 \\
\hline \multirow{3}{*}{$\begin{aligned} \text { p value for } 2 \text { years: before } & \\
& \text { after } \\
& \text { before and after }\end{aligned}$} & 0.21 & 0.30 \\
\hline & 0.50 & 0.46 \\
\hline & 0.30 & 0.36 \\
\hline
\end{tabular}

Table 6. Results of the Superposed Epoch Analysis of the NAO key events as related to the log-abundance of Calanus finmarchicus. Epoch analyses were computed as in Table 5

\begin{tabular}{|c|c|c|c|}
\hline Numb & r of key events: & $\begin{array}{c}\text { High NAO } \\
5\end{array}$ & $\begin{array}{c}\text { Low NAO } \\
8\end{array}$ \\
\hline \multirow[t]{2}{*}{$p$ value for 1 year: } & $\begin{array}{l}\text { before } \\
\text { after }\end{array}$ & $\begin{array}{c}0.2 \\
0.05 \\
(W=-1.9)\end{array}$ & $\begin{array}{c}0.07 \\
0.3\end{array}$ \\
\hline & before and after & 0.08 & 0.08 \\
\hline \multirow[t]{3}{*}{$p$ value for 2 years } & before & 0.24 & $\begin{array}{c}0.03 \\
(W=1.8)\end{array}$ \\
\hline & after & $\begin{array}{c}0.007 \\
(W=-2.9)\end{array}$ & $\begin{array}{c}0.07 \\
(W=2.4)\end{array}$ \\
\hline & before and after & $\begin{array}{c}0.04 \\
(W=-2.4)\end{array}$ & $\begin{array}{c}0.01 \\
(W=2.8)\end{array}$ \\
\hline
\end{tabular}

spring. During this period, the association between the $\mathrm{NAO}$ and $C$. finmarchicus was conspicuous (Fig. 6c): years of high NAO were related to very low abundance and a very short seasonal cycle, restricted to April, whereas years of low NAO corresponded to very high abundance from April to August. Hence, a mismatch might occur between fish larvae and $C$. finmarchicus during the high NAO years. From 1958 to 1992, non-detrended series of cod and pollack and C. finmarchicus were significantly correlated at the $5 \%$ level (Table 4 ), but the correlation vanished when it was computed on detrended series (Table 4). Results
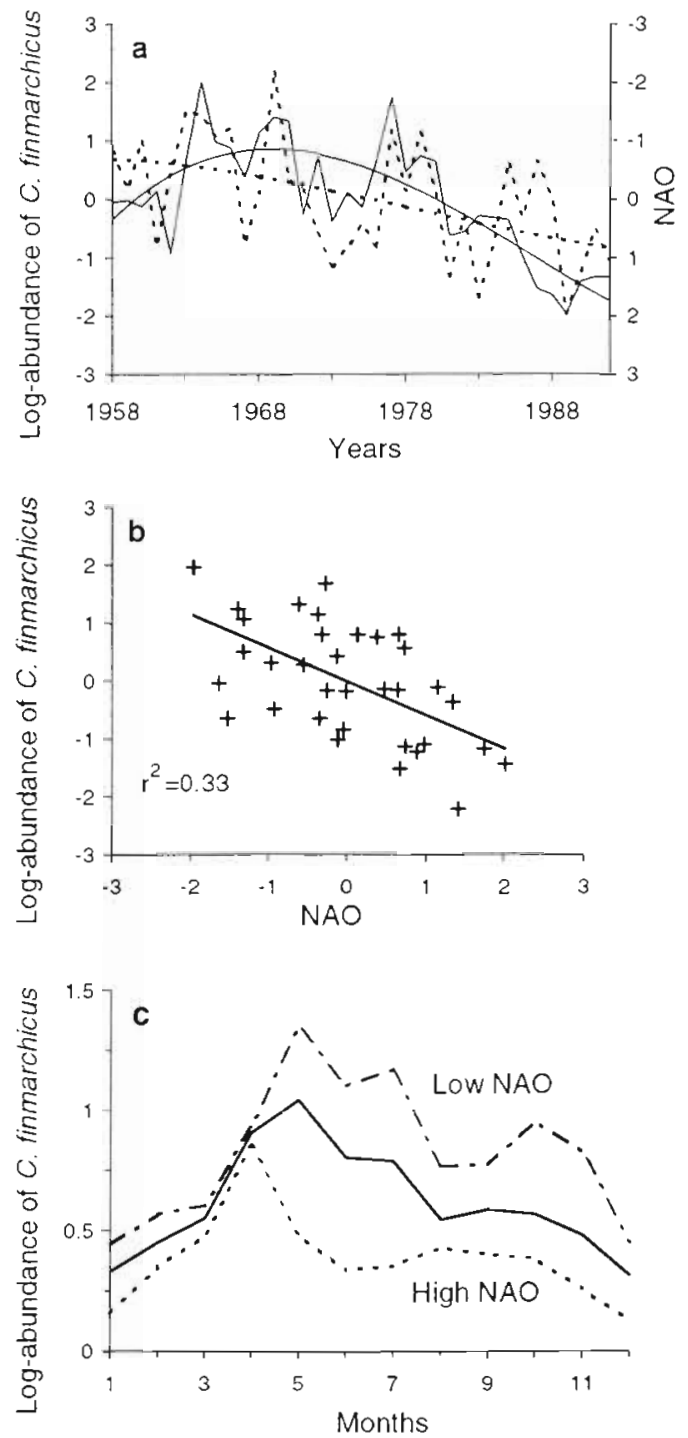

Fig. 6. (a) Annual average of the log-abundance of Calanus finmarchicus in the Skagerrak from 1958 to 1992. The NAO index for the corresponding period is shown by the superimposed dotted line on an inverted scale. The 2 series were previously standardised. The trends are estimated by a thirdorder polynomial function. (b) Linear regression plots of the NAO index versus C. finmarchicus. (c) Mean seasonal cycle of C. finmarchicus from 1958 to 1992 (solid line), during the extreme high NAO years (dotted line) and extreme low NAO years (dash-dotted line)

from SEA showed no association between the extreme high or low abundance of $C$. finmarchicus and abundance of cod (Table $7 \mathrm{a}$ ). The abundance of pollack was statistically lower during extreme low abundance of C. finmarchicus than during the following years (Table 7b). However, the abundance of pollack was not significantly lower when key-event years were compared with surrounding years instead of the following years alone (Table $7 \mathrm{~b}$ ). 


\section{DISCUSSION}

\section{Spatial scales of long- and short-term fluctuations}

Mantel statistics showed that the short-term fluctuations (ca 2 to $5 \mathrm{yr}$ ) exhibited significant similarities at a local scale: 0 to $21 \mathrm{~km}$. Because biotic interactions are known to take place at a local scale (Caley et al. 1996), this result corroborates the hypothesis that short-term fluctuations in Norwegian Skagerrak cod and pollack were related to biotic factors, i.e. competition and/or cannibalism within the juvenile stages (Fromentin et al. 1997, Bjornstad et al. unpubl., Stenseth et al. unpubl.). This result is further consistent with the spatial extent of the optimal habitats of both fishes, which do not exceed $20 \mathrm{~km}$ (Fromentin et al. 1997).

In contrast, long-term fluctuations of cod and pollack did not display significant similarity at a local scale. The patterns of the long-term trends must be seen as a global feature across the Norwegian Skagerrak coast. The relative importance of biotic and abiotic factors regulating the temporal patterns of marine populations is generally assumed to vary with scale (Menge \& Olson 1990, Caley et al. 1996). At a local scale, both abiotic and biotic factors influence the patterns, whereas at a larger scale the relative importance of abiotic factors increases. This argument, together with the fact that the literature often refers to external influences to explain trends in fish populations, either through overfishing (e.g. Garrod \& Schumacher 1994, Myers et al. 1996), variations in food availability (e.g.

Table 7. Results of the Superposed Epoch Analysis on the Calanus finmarchicus key events as related to the log-abundance of (a) cod and (b) pollack. Epoch analyses were computed as in Table 5

\begin{tabular}{|c|c|c|c|}
\hline \multicolumn{2}{|c|}{ Number of key events: } & $\begin{array}{l}\text { High abundance of } \\
\text { C. finmarchicus } \\
5\end{array}$ & $\begin{array}{l}\text { Low abundance of } \\
\text { C. finmarchicus } \\
5\end{array}$ \\
\hline \multicolumn{4}{|l|}{ (a) Cod } \\
\hline \multirow[t]{3}{*}{$p$ value for 1 year: } & before & 0.30 & 0.47 \\
\hline & after & 0.41 & 0.50 \\
\hline & before and after & 0.32 & 0.47 \\
\hline \multirow[t]{3}{*}{$p$ value for 2 years: } & before & 0.36 & 0.45 \\
\hline & after & 0.23 & 0.38 \\
\hline & before and after & 0.44 & 0.39 \\
\hline \multicolumn{4}{|l|}{ (b) Pollack } \\
\hline \multirow[t]{3}{*}{ p value for 1 year: } & before & 0.31 & 0.29 \\
\hline & after & 0.49 & $\begin{array}{c}0.05 \\
(W=-1.3)\end{array}$ \\
\hline & before and after & 0.36 & 0.20 \\
\hline \multirow[t]{3}{*}{$p$ value for 2 years: } & before & 0.57 & 0.21 \\
\hline & after & 0.52 & $\begin{array}{c}0.05 \\
(W=-1.9)\end{array}$ \\
\hline & before and after & 0.49 & 0.26 \\
\hline
\end{tabular}

Skreslet 1989, Cushing 1995, Sundby 1995), or climatic and hydrographic changes (e.g. Koslow \& Tompson 1987, Cury \& Roy 1989, Ellersten et al. 1989, Dickson \& Brander 1993, Mann 1993, Ottersen \& Sundby 1995), leads us to postulate that the long-term fluctuations have, in contrast to short-term ones, an extrinsic origin.

\section{Relationship between the NAO, Calanus finmarchicus, and cod and pollack}

Winter fluctuations in AT, SST and WW were homogeneous along the Norwegian Skagerrak coast and were closely associated with the NAO. Higher AT and SST as well as stronger WW than normal along the coast were related to high NAO, whereas lower AT, SST and WW were related to low NAO. However, trends and year-to-year fluctuations in cod and pollack abundance did not correspond to those of the NAO. No association between extreme NAO events and abundance of cod and pollack was detected either. In order to confirm this lack of relationship, we also computed correlation analyses and SEA between each meteorological variable and cod and pollack (results not shown), and no associations emerged in any of the comparisons.

No direct associations were found between the NAO and cod or pollack. However, indirect relationships, through an influence of the NAO on zooplankton, might be possible. Indeed, Calanus finmarchicus in the Skagerrak was related to the NAO, as shown by Fromentin \& Planque (1996) over the Northeast Atlantic. During high NAO, C. finmarchicus in the Skagerrak displayed low abundance and a shorter seasonal cycle limited to April. In contrast, during years of low NAO, this species exhibited high abundance from April to August. C. finmarchicus, cod and pollack displayed a similar downward trend from 1958 to 1992 but year-to-year fluctuations were not synchronous. Under the hypothesis that the recent decline of cod and pollack might be related to the decrease of $C$. finmarchicus (and assuming that C. finmarchicus represents the major component of fish larvae diets), low abundance of fish should at least be associated with low abundance of $C$. finmarchicus. This was obviously not the case for cod, but abundance of pollack was statistically lower during extreme low abundance of $C$. finmarchicus than in the following years. 
Because this relationship did not remain when the test was computed with surrounding years instead of the following years alone, and because this relationship is lacking for cod, we conclude that there is no strong and clear evidence to support the hypothesis of a relationship between the decline of cod or pollack and the decrease of $C$. finmarchicus.

\section{Hypotheses concerning the lack of association between the NAO and cod and pollack}

As discussed in the introduction, there are good reasons to expect that large-scale climatic changes, such as the NAO, may influence fish stocks. Biological and ecological characteristics of these populations might explain why such a relationship did not emerge. First, the geographical distribution of cod and pollack extends approximately from the north of the Bay of Biscay to the south of Iceland (Svetovidov 1986). The Norwegian Skagerrak populations are in the middle of these distributions. The consequences of fluctuations in temperature are, therefore, likely to be less important for the Norwegian Skagerrak populations than for other populations that are nearer the southern or northern geographical boundaries (such as the Arcto-Norwegian cod; Ellertsen et al. 1989, Ottersen \& Sundby 1995). Second, large-scale climatic changes also seem to affect fish populations through expatriation because of variations in the windfield (see for instance the case of the Iceland-Greenland-Labrador stocks; Dickson \& Brander 1993). This class of processes is likely to be less pronounced for coastal and enclosed populations than for open sea populations, because the former are less exposed to large-scale advective processes than the latter. It is difficult to argue about the lack of association between Calanus finmarchicus and 0-group cod and pollack, because of our poor knowledge on zooplanktonic production within the fjords of the Norwegian Skagerrak coast. One possible explanation might be that there was a significant local production of various zooplanktonic species consumed by fish larvae which was not sampled by the CPR.

The importance of large-scale climatic changes for population dynamics probably depends on the proportion of the variability explained by this kind of event in comparison to other environmental factors. In other words, if a given external factor that is important for fish has varied with a higher amplitude than the NAO, one can suppose that this factor would act primarily on fish and that the NAO would then be of minor importance. Therefore, we hypothesised that the cause(s) of the trends in the Norwegian Skagerrak cod and pollack were associated with large-scale extrinsic factors other than the NAO.

\section{Alternative hypothesis: long-term variations in the sea grass coverage}

At the beginning of the 1930 s, a sea grass disease affecting Zostera marina destroyed much of the bottom flora coverage along the Skagerrak coast (Johannessen \& Sollie 1994). The very low levels during the thirties reflect this disease (Fig. 7). From 1945 to 1965 , the bottom flora has increased regularly to attain high levels. It remained constant until the end of the seventies, and slightly decreased during the eighties. The long-term trends of the bottom flora coverage correspond to the trend in cod and pollack abundance. This correspondence might be a result of a causal relationship. Unfortunately, quantitative statistics on bottom coverage were not possible because the data result from qualitative observations and not real measurements. Therefore, only the shape of the trend is trustworthy (Johannessen pers, comm.). However, this hypothesis is consistent with the results of the Mantel correlograms, since the long-term fluctuations in $Z$. marina occurred throughout the entire Norwegian Skagerrak coast. Furthermore, several ecological arguments also support this hypothesis. First, juveniles primarily feed on the fauna associated with the sea grass bed, mainly crustaceans and small fishes (Fjøsne \& Gjøsæeter 1996). Second, these populations have strong habitat preferences (Fromentin et al. 1997), and these habitats are mainly constituted by the sea grass beds (Johannessen \& Sollie 1994). Third, the survival of the 0-group cod was density-dependent (Bjørnstad et al. unpubl., Stenseth et al. unpubl.), possibly due to competition for habitat. Notice that competition for habitat, which may involve food limitation or increased predation risk (Wootton 1990), has already been documented to be high in sea grass beds (Tupper \& Boutilier 1995, 1997). Thus, a sudden and severe

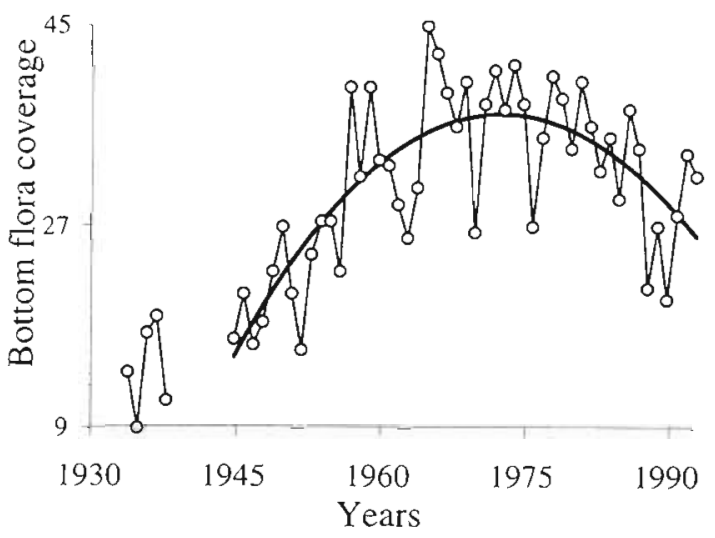

Fig. 7. Average bottom flora coverage from 1934 to 1993 (qualitative data and arbitrary unit). The trend is estimated by a third-order polynomial function 


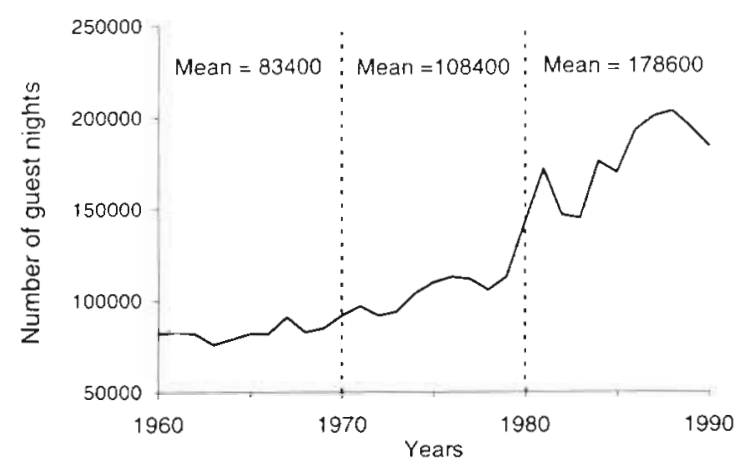

Fig. 8. Number of guest nights in the hotels along the Norwegian Skagerrak coast. (Statistics from Lystad 1991)

reduction of the bottom flora coverage (such as that following the sea grass disease from the 1930s; see Fig. 5) might reduce the density of cod and pollack by increasing food limitation, competition and/or predation risk for the 0-group, whereas the subsequent spatial extension of the sea grass after the war might have had the opposite effect.

Fluctuations in Zostera marina could, however, hardly explain the dramatic decline in cod and pollack since the mid-seventies (even if the bottom flora coverage also decreased during this period). This decline might be related to overfishing Local fisheries and non-commercial fishing (i.e. related to local human population and tourism) are primarily linked to cod and secondarily to pollack on the Norwegian Skagerrak coast. The number of fishermen has decreased during the last 20 yr (Anon 1993), but efficiency in catch might have remained constant or increased. Non-commercial fishing has probably increased during the last 2 decades, partially in relation to a tremendous growth of tourism since the $1980 \mathrm{~s}$ (Fig. 8). Indeed, recent analyses on mark-recapture data showed that recreational and artisanal fishing induced a very high mortality in the adults of the Norwegian Skagerrak cod (R. Julliard et al. unpubl.). As 'recruitment overfishing' (i.e. decline in recruitment and early stages due to overfishing through the parent stocks) appears to be a common problem for most of the North Atlantic populations (Myers \& Barrowman 1996), we could not dismiss the hypothesis that the recent decline in the o-group cod and pollack was (partially) related to overfishing.

\section{CONCLUSION}

On the basis of various analyses, we concluded that: (1) Factors causing the long-term fluctuations in the Norwegian Skagerrak cod and pollack were of extrin- sic origin and took place at a scale equal to or larger than the Norwegian Skagerrak coast. (2) Climatic conditions along the Norwegian Skagerrak coast as well as the fluctuations of Calanus finmarchicus in the Skagerrak were closely associated with the NAO. (3) Long-term fluctuations of cod and pollack were not associated with the NAO or with the decrease of $C$. finmarchicus. (4) Trends of cod and pollack might, however, be related to the long-term fluctuations of the bottom flora coverage and fishing. Finally, the postsettlement period appeared to be crucial for these populations, because of competition for space which might involve food limitation or increased predation risk.

Acknowledgements. First of all, our appreciation goes to the late Rangvald Løversen and to Aadne Sollie for carrying out the sampling resulting in the 'Flødevigen data set' Thanks are due to a DN-funded project for organising the data into computer-readable format and to Stein Kristiansen from the Norwegian Meteorological Institute for providing meteorological data. Financial support from the University of Oslo (through the 'Environmental Program' to N.C.S.) and from the MAST program of the European Union (fellowship contract to J.M.F.) made the reported analyses possible. We also thank $O$. N. Bjørnstad for his helpful remarks on the manuscript and various discussions as well as the anonymous referees for their constructive comments.

\section{LITERATURE CITED}

Alexander MA, Deser C (1995) A mechanism for the recurrence of wintertime midlatitude SST anomalies. J Phys Oceanogr 25:122-137

Anon (1993) Handlingsplan for fiskerinæringen på Skagerrakkysten ogi Rogaland. Skagerrakkysten Fp Kristiansand

Bartlett MS (1946) On the theoretical specification of sampling properties of autocorrelated time series. J Res Stat Soc Suppl 8:24-411

Beamish RJ, Bouilion DR (1993) Pacific salmon production trends in relation to climate. Can J Fish Aquat Sci 50: $1.002-1016$

Brander KM (1995) The effect of temperature on growth of Atlantic cod (Gadus morhua, L.). ICES J Mar Sci 52:1-10

Brander K, Hurley PCF (1992) Distribution of early-stage Atlantic cod (Gadus morhua), haddock (Melanogrammus aeglefinus) and witch flounder (Glyptocephalus cynogiossus\} eggs on the Scotian Shelf: a reappraisal of evidence on the coupling of cod spawning and plankton production. Can J Fish Aquat Sci 49:238-251

Caley MJ, Carr MH, Hixon MA, Hughes TP, Jones GP, Menge BA (1996) Recruitment and the local dynamics of open marine populations. Annu Rev Ecol Syst 27:477-500

Cayan DR (1992a) Latent and sensible heat flux anomalies over the northern oceans: driving the sea surface temperature. J Phys Oceanogr 22:859-881

Cayan DR (1992b) Latent and sensible heat flux anomalies over the northern oceans: the connection to monthly atmospheric circulation. J Clim 5:354-369

Cury P, Roy C (1989) Optimal environmental window and pelagic fish recruitment success in upwelling areas. Can J Fish Aquat Sci 46:670-680

Cushing DH (1989) A difference in structure between ecosys- 
tems in strongly stratified waters and in those that are only weakly stratified. J Plankton Res 11:1-13

Cushing DH (1990) Plankton production and year class strength in fish populations: an update of the match/mismatch hypothesis. Adv Mar Biol 26:249-293

Cushing DH (1995) The long-term relationship between zooplankton and fish. ICES J Mar Sci 52:611-626

Dickson RR, Brander KM (1993) Effects of a changing windfield on cod stocks of the North Atlantic. Fish Oceanogr 2: $124-153$

Dickson RR, Kelly PM, Colebrook JM, Wooster WS, Cushing DH (1988) North winds and production in the eastern north Atlantic. J Plankton Res 10:151-169

Dickson RR, Lazier J, Meincke J, Rhines P, Swift J (1996) Long-term coordinated changes in the convective activity of the North Atlantic. Prog Oceanogr 38:241-295

Ellertsen B, Fossum P, Solemdal P, Sundby S (1989) Relation between temperature and survival of eggs and firstfeeding larvae of northeast Arctic cod (Gadus morhua L.). Rapp PV Réun Cons lnt Explor Mer 191:209-219

Ellertsen B, Solemdal P, Sundby S, Tilseth S, Westgård $T$, Oiestad V (1981) Feeding and vertical distribution of cod larvae in relation to availability of prey organisms. Rapp PV Réun Cons Int Explor Mer 178:317-319

Fjøsne K, Gjøsæter J (1996) Dietary composition and the potential of food competition between 0-group cod (Gadus morhua L.) and some other fish species in the littoral zone. ICES J Mar Sci 53:757-770

Fromentin JM, Planque B (1996) Calanus and environment in the eastern North Atlantic. II. Role of the North Atlantic Oscillation on Calanus finmarchicus and C. helgolandicus. Mar Ecol Prog Ser 134:111-118

Fromentin JM, Stenseth NC, Gjøsæter J, Bjornstad O, Falk W, Johannessen $T$ (1997) Spatial patterns of the temporal dynamics of three gadoids species along the Norwegian Skagerrak coast. Mar Ecol Prog Ser 155:209-222

Garrod DJ, Schumacher A (1994) North Atlantic cod: a broad canvas. ICES Mar Sci Symp 98.59-76

Gjøsæter J (1990) Norwegian coastal Skagerrak cod. Report on the ICES study group of cod stock fluctuations. Appendix III. Comm Mtg Int Explor Sea ICES CM G50:155-170

Harris GP, Griffiths FB, Clemenston LA (1992) Climate and fisheries off Tasmania-interactions of physics, food chains and fish. In: Payne AlL et al. (eds) Benguela trophic functioning. S Afr J Mar Sci 12:107-121

Haurwitz MW, Prager MH, Payton NB (1981) A critique of the superposed epoch analysis method: its application to solar-weather relations. Mon Weather Rev 109:2074-2079

Hirche HJ (1987) Temperature and plankton. II. Effects on respiration and swimming activity in copepods from Greenland Sea. Mar Biol 94:347-356

Hurrell JW (1995) Decadal trends in the North Atlantic Oscillation: regional temperatures and precipitations. Science 269:676-679

Hurrell JW, Van Loon H (1998) Decadal variations in climate associated with the North Atlantic Oscillation. Clim Change (in press)

Johannessen T, Dahl E (1996) Declines in oxygen concentrations along the Norwegian Skagerrak coast, 1927-1993: a signal of ecosystem changes due to eutrophication? Limnol Oceanogr 41:766-778

Johannessen T, Sollie A (1994) Overvåking av gruntvannsfauna pả Skagerrakkysten. Fisken Havet 10

Koslow JA, Tompson KR (1987) Recruitment to Northwest Atlantic cod (Gadus morhua) and haddock (Melanogrammus aeglefinus) stocks: influence of stocks size and climate. Can J Fish Aquat Sci 44:26-39
Lamb PJ, Randy AP (1987) North Atlantic Oscillation: concept and an application. Bull Am Meteorol Soc 68:1218-1225

Lasker R (1981) Factors contributing to variable recruitment of the Northern anchovy (Engraulis mordax) in the California current: contrasting years, 1975 through 1978. Rapp PV Réun Cons Int Explor Mer 178:375-388

Legendre P, Fortin MJ (1989) Spatial pattern and ecological analysis. Vegetatio 80:107-138

Lindahl O, Hernroth L (1988) Large-scale and long-term variations in the zooplankton community of the Gullmar fjord, Sweden, in relation to advective processes. Mar Ecol Prog Ser 43:161-171

Lystad JA (1991) Norsk hotellnæring 1950-1990. Central Bureau of Statistics, Oslo

Mann KH (1993) Physical oceanography, food chains, and fish stocks: a review. ICES J Mar Sci 50:105-119

Mann KH, Lazier JRN (1991) Dynamics of marine ecosystems. Biological-physical interactions in the oceans. Blackwell Scientific Publications, Oxford

Mantel $N$ (1967) The detection of disease clustering and a generalized regression approach. Cancer Res 27: $209-220$

Menge BA, Olson AM (1990) Role of scale and environmental factors in regulation of community structure. Trends Ecol Evol 5:52-57

Myers RA, Barrowman NJ (1996) Is fish recruitment related to spawner abundance? Fish Bull US 94:707-724

Myers RA, Hutchings JA, Barrowman NJ (1996) Hypotheses for the decline of the cod in the North Atlantic. Mar Ecol Prog Ser 138:293-308

Myers RA, Mertz G, Barrowman NJ (1995) Spatial scales of variability in cod recruitment in the North Atlantic. Can J Fish Aquat Sci 52:1849-186

Myers RA, Mertz G, Bishop CA (1993) Cod spawning in relation to physical and biological cycles of the northern North-west Atlantic. Fish Oceanogr 2(3/4):154-165

Ostrom CW (1987) Time series analysis: regression techniques. Sage publications, Beverly Hills

Ottersen G, Sundby $\mathrm{S}$ (1995) Effects of temperature, wind and spawning stock biomass on recruitment of Arcto-Norwegian cod. Fish Oceanogr 4:278-292

Planque B, Fromentin JM (1996) Calanus and environment in the eastern North Atlantic. I. Spatial and temporal patterns of Calanus finmarchicus and C. helgolandicus. Mar Ecol Prog Ser 134:101-109

Prager M, Hoenig J (1989) Superposed epoch analysis: a randomization test of environmental effects on recruitment with application to chub mackerel. Trans Am Fish Soc 118: 608-618

Priestley MB (1981) Spectral analysis and times series. Academic Press, London

Rogers JC (1984) The association between the North Atlantic Oscillation and the Southern Oscillation in the Northern Hemisphere. Mon Weather Rev 112:1999-2015

Rogers JC (1990) Patterns of low-frequency monthly sea level pressure variability $(1899-1986)$ and associated wave cyclone frequencies. J Clim 3:1364-1379

Schlesinger ME, Ramankutty N (1994) An oscillation in the global climate system of period $65-70$ years. Nature 367 : 723-726

Sen A, Srivastava M (1990) Regression analysis: theory, methods and applications. Springer-Verlag, New York

Skreslet S (1989) Spatial match and mismatch between larvae of cod (Gadus morhua L.) and their principal prey, nauplii of Calanus finmarchicus (Gunnerus). Rapp PV Réun Cons Int Explor Mer 191:258-263

Smouse PE, Long JC, Sokal RR (1986) Multiple regression and 
correlation extensions of Mantel test of matrix correspondence. Syst Zool 35:627-632

Sokal RR (1986) Spatial data analysis and historical processes. In: Diday $E$ et al. (eds) Data analysis and informatics, Vol IV. North Holland, Amsterdam, p 29-43

Sundby S (1995) Wind climate and foraging of larval and juvenile Arcto-Norwegian cod (Gadus morhua). In: Beamish RJ (ed) Climate change and northern fish populations. Can Spec Publ Fish Aquat Sci 121:405-415

Sverdrup HU (1953) On conditions for the vernal blooming of phytoplankton. J Cons Int Explor Mer 18:287-295

Svetovidov AN (1986) Gadidae. In: Whitehead PJP (ed) Fishes of the North-eastern Atlantic and the Mediterranean, Vol 2. UNESCO, Paris, p 680-710

Tupper M, Boutilier RG (1995) Effects of habitat on settle-

Editorial responsibility: Otto Kinne (Editor),

Oldendorf/Luhe, Germany ment, growth, and postsettlement survival of Atlantic cod (Gadus morhua). Can J Fish Aquat Sci 52:1834-1841.

Tupper M. Boutilier RG (1997) Effects of habitat on settlement, growth, predation risk and survival of a temperate reef fish. Mar Ecol Prog Ser 151:225-236

Warner AJ, Hays GC (1994) Sampling by the continuous plankton recorder survey. Prog Oceanogr 34:237-256

Williamson $M$ (1972) The analysis of biological populations Edward Arnold, London

Wootton RJ (1990) Ecology of teleost fishes. Chapman \& Hall London

Zagoruiko NG, Yolkina VN (1982) Inference and data tables with missing values. In: Krishnaiah PR, Kanal LN (ed) Handbook of statistics, Vol 2. North Holland, Amsterdam, p 493-500

Submitted: April 30, 1997; Accepted: November 21, 1997 Proofs received from author(s): January 26, 1998 